\title{
Política de imigração: A regulação dos fluxos
}

Immigration policy: The regulation of fluxes

Politique d'immigration : la régulation des flux

\section{Maria loannis Baganha}

\section{CpenEdition}

\section{Journals}

Edição electrónica

URL: http://journals.openedition.org/rccs/952

DOI: $10.4000 /$ rccs. 952

ISSN: 2182-7435

\section{Editora}

Centro de Estudos Sociais da Universidade de Coimbra

\section{Edição impressa}

Data de publição: 1 dezembro 2005

Paginação: 29-44

ISSN: 0254-1106

\section{Refêrencia eletrónica}

Maria loannis Baganha, « Política de imigração: A regulação dos fluxos », Revista Crítica de Ciências Sociais [Online], 73 | 2005, posto online no dia 01 outubro 2012, consultado o 10 dezembro 2020. URL : http://journals.openedition.org/rccs/952 ; DOI : https://doi.org/10.4000/rccs.952 


\section{Política de imigração: A regulação dos fluxos}

O presente artigo tem como principal objectivo analisar como é que os vários governos, desde a entrada de Portugal na Comunidade Europeia até hoje, regularam a imigração e quais os objectivos que se propuseram atingir com essa regulação. $O$ trabalho baseia-se essencialmente na análise de dois acervos documentais, a saber: documentos legais que enquadram a entrada em território nacional de imigrantes não comunitários, bem como os diplomas legais que estabeleceram períodos de regularização extraordinária de estrangeiros ilegais; e intervenções governamentais na Assembleia da República aquando da apresentação de pedidos de autorização legislativa relativos à entrada em território nacional de estrangeiros não comunitários ou ao lançamento de campanhas de regularização de estrangeiros em situação de ilegalidade. Com base na análise da documentação referida, a autora defende que a política de regulação dos fluxos nunca atingiu os seus objectivos, tendo o sistema de regulação falhado sucessivamente, obrigando a períodos de legalização extraordinária.

\section{Introdução}

A dispersão generalizada de informação sobre as diferenças de oportunidades, quer a nível económico, quer no acesso a um conjunto de bens e serviços que asseguram diferentes níveis de bem-estar, e a existência de redes globais de tráfico e de transporte de imigrantes fizeram e continuarão a fazer crescer drasticamente a pressão migratória dos países pobres para os países ricos.

Dado o enorme diferencial de bem-estar entre os indivíduos a viver em países com diferentes níveis de desenvolvimento (a raiz de todas as migrações económicas), a livre entrada nos países desenvolvidos induziria fluxos ilimitados, levando a um afundamento no sentido da igualização mundial e, também, a uma queda violenta nos níveis de emprego e consumo desses mesmos países (Zolberg, 1989). Não admira, assim, que a esmagadora maioria das forças políticas não defenda políticas migratórias de porta aberta.

De facto, os Estados, no exercício dos seus direitos de soberania, definem políticas migratórias, mais ou menos restritivas, ao estabelecerem e controlarem quem pode entrar e permanecer no seu território e, subsequente- 
mente, pertencer ao todo nacional. No exercício destes direitos, os Estados promulgam e implementam legislação que visa regulamentar os seguintes aspectos da relação cidadão estrangeiro/Estado nacional: entrada, permanência, aquisição de nacionalidade e expulsão do território nacional.

E porque assim é, qualquer política migratória tem que começar por resolver duas questões de natureza totalmente diversa, uma vez que uma é de ordem quantitativa, isto é, quantos imigrantes deve o país receber, e a outra é de carácter qualitativo, ou seja, qual deve ser o perfil dessas pessoas. Como afirma G. Borjas (1996), a política a ser implementada depende da forma como se tentar resolver estas duas questões, ou seja, depende do bem-estar que se pretende promover - o dos nacionais, o dos imigrantes, o do resto do mundo, ou uma das possíveis combinações destes três.

Assim sendo, a estruturação de uma política migratória nacional passa antes de mais pela resposta que for dada à seguinte pergunta: como deverá Portugal regular os fluxos migratórios de entrada?

1 - de acordo com a pressão migratória existente, isto é, de acordo com a oferta e preocupações predominantemente humanitárias?

2 - deverá privilegiar uma vertente geoestratégica, mantendo a discriminação positiva em relação aos Países Africanos de Língua Oficial Portuguesa (PALOP) e ao Brasil?

3 - deverá regular as novas correntes de acordo com a procura, isto é, de acordo com as necessidades do mercado de trabalho nacional?

Só sendo capaz de responder politicamente a esta questão será possível elaborar e vir a implementar uma política migratória consistente, uma vez que a regulação da permanência dos imigrantes em território nacional e a determinação dos mecanismos que irão permitir e facilitar a integração e a pertença à sociedade portuguesa estão necessariamente dependentes do número e do tipo de imigrantes que forem autorizados a entrar.

O presente artigo tem como principal objectivo analisar como foi sendo respondida esta pergunta, desde a entrada de Portugal na Comunidade Europeia em 1986 até aos nossos dias. Mais concretamente, pretende-se analisar como é que os vários governos regularam a imigração e quais os objectivos que se propuseram atingir com essa regulação.

A forma como foi regulada a imigração em Portugal encontra-se explanada nos documentos legais que enquadram a entrada em território nacional de imigrantes não comunitários, bem como nos diplomas legais que estabeleceram períodos de regularização extraordinária de estrangeiros ilegais. Mais do que nestes documentos, os objectivos a atingir com esta regulação encontram-se explicitados nas várias intervenções governamen- 
tais na Assembleia da República aquando da apresentação de pedidos de autorização legislativa relativos à entrada em território nacional de estrangeiros não comunitários ou ao lançamento de campanhas de regularização de estrangeiros em situação de ilegalidade. São pois estes dois acervos documentais que servem essencialmente de base à reflexão que se segue.

\section{Antecedentes históricos}

O fim do império colonial português provocou o retorno a Portugal de aproximadamente 500 mil nacionais, dos quais se estima que 59\% tinham nascido na metrópole. Os restantes $41 \%$ incluíam os seus descendentes, bem como pessoas de naturalidade e ancestralidade africana de nacionalidade portuguesa (Pires et al., 1984). Este último grupo de retornados veio, naturalmente, aumentar o número de portugueses de descendência africana residentes em território nacional.

O Decreto-Lei n. ${ }^{\circ}$ 308-A/75, de 24 de Julho, ao retirar a nacionalidade portuguesa a uma parte substancial destes portugueses, criou retroactivamente uma comunidade estrangeira, "imigrante", de ancestralidade africana, que vai subsequentemente crescer devido a um processo de reunificação familiar.

Assim, a presença em 1981 de 27 mil nacionais dos PALOP, que representavam $43 \%$ da população estrangeira legalmente residente em território nacional, podia ser essencialmente atribuída ao retorno involuntário à "Metrópole do Império", no momento em que o mesmo se fragmentava em Estados soberanos, e à perda de nacionalidade portuguesa imposta pelo Decreto-Lei n. ${ }^{\circ}$ 308-A/75.

Sob o impacto da entrada de Portugal na Comunidade Europeia, em 1986, nomeadamente dos investimentos na construção de infra-estruturas que desde então se começaram a verificar, as oportunidades de trabalho indiferenciado vão crescer acentuadamente no mercado de trabalho nacional. Estas novas oportunidades veiculadas pelas redes de carácter informal, que uniam estas comunidades de ancestralidade africana às suas comunidades de origem, vão atrair ao mercado de trabalho nacional um número crescente de familiares e conterrâneos que tinham permanecido, após a independência, nos seus próprios países.

E porque o mecanismo de entrada legal mais expedito e eficaz era o recurso aos vistos de curta duração (turismo, motivos de saúde, acompanhar doentes, estudo, etc.), vai, com este tipo de visto, radicar-se em território nacional e, sobretudo, na Área Metropolitana de Lisboa, um número crescente de imigrantes dos PALOP sem autorizações de residência. Ou seja, formou-se uma bolsa de clandestinos, que desde meados dos anos oitenta 
cresceu ininterruptamente e cuja presença era tanto do conhecimento público como das autoridades competentes. ${ }^{1}$ Apesar desse conhecimento, não houve, até aos inícios dos anos noventa, por parte do poder central qualquer iniciativa legislativa para regular o fluxo migratório ou a presença crescente de imigrantes ilegais em território nacional. Esta inacção não nos deve surpreender, pois, como afirmou Hammar (1992: 256), quando os fluxos não são vistos como uma ameaça basta uma "não política".

\section{A fase da Imigração Zero}

A entrada de Portugal na Comunidade Europeia e a adesão ao Acordo de Schengen obrigou a um novo enquadramento jurídico das migrações para Portugal. Aproveitando a ocasião, o então ministro da Administração Interna, Dias Loureiro, subscreveu os seguintes objectivos para a política migratória de regulação dos fluxos: lançamento de um processo de Regulação Extraordinária, que incluía medidas de discriminação positiva em relação aos nacionais de países de língua oficial portuguesa (Decreto-Lei n. ${ }^{\circ}$ 212/92 de 12 de Outubro) e subsequente implementação de legislação restritiva à entrada de imigrantes económicos (Decreto-Lei n. ${ }^{\circ}$ 59/93, de 3 de Março).

Como foi então afirmado pelo ministro da Administração Interna, o objectivo político era "limitar, de forma criteriosa e prudente, a fixação de novos imigrantes" 2 . Este limite era tendencialmente de zero, como mais tarde o Ministro veio a clarificar: "não receber mais imigrantes sem integrar as comunidades que já existem no país" (citação de Dias Loureiro, no Público, 13 de Novembro de 1993).

Assim, a primeira regulação explícita dos fluxos migratórios após a entrada de Portugal na Comunidade Europeia tinha como objectivo uma política de "imigração zero", tão restritiva e selectiva nas entradas que, na prática, estancasse o fluxo migratório (excepto para efeitos de reunificação familiar) e impedisse a fixação de ilegais em território nacional.

Apesar da retórica e do novo enquadramento legal, nada de substancial foi alterado na concessão de vistos de curta duração e os imigrantes, particularmente dos PALOP, continuaram a entrar e a fixar-se ilegalmente como haviam feito no decurso da década de oitenta, só que agora em maior número, como reconhecem os Relatórios de Segurança Interna deste período.

\footnotetext{
${ }^{1}$ Vejam-se por exemplo os artigos sobre este tema publicados no Público de 17 de Julho de 1990 e no Diário de Notícias de 15 de Outubro de 1991.

${ }^{2}$ Intervenção do ministro da Administração Interna, Dias Loureiro, na Assembleia da República, in Diário da Assembleia da República, 27 de Março de 1992: 1367.
} 


\section{A fase dos interesses geoestratégicos e das considerações humanitárias}

Criou-se uma nova bolsa de ilegais e, passados quatro anos, a Assembleia da República aprovou por unanimidade um novo processo de Regularização Extraordinária, desta vez legitimado politicamente pela necessidade de legalizar os imigrantes que não tinham sido abrangidos pela anterior Regularização de 1992/93 ou que, entretanto, se tinham tornado ilegais (Lei n. ${ }^{\circ} 17 / 96$, de 24 de Maio).

O governo defendeu este novo processo de regularização baseado em três pressupostos: promover a futura cooperação e amizade com os países africanos de expressão portuguesa e com o Brasil; colocar um ponto final no processo de exclusão dos imigrantes irregulares relativamente ao modelo social europeu (nomeadamente a protecção social e laboral); e garantir menores níveis de risco para os portugueses ameaçados pelo crescimento da marginalização e da exclusão provocadas pela imigração clandestina. ${ }^{3}$

Dada a abertura e envolvimento da sociedade civil no processo de Regularização de 1996, em que foram recebidos 35 mil processos, dos quais mais de $90 \%$ deram lugar à emissão de um título de residência, tudo indica que o número de ilegais deverá ter decrescido drasticamente, pelo menos imediatamente após a Regularização Extraordinária de 1996.

Convém contudo notar que a entrada em vigor, em Março de 1995, da Convenção de Aplicação de Schengen fez cessar a exigência de consulta prévia obrigatória para a concessão de visto aos nacionais da Rússia, Ucrânia, Roménia e outros países do Leste Europeu, o que, conjugado com a liberdade de circulação no Espaço Schengen, potenciou a vinda para o nosso país de migrantes provenientes dessa região. A revisão, em 1998, da Lei de Entrada, Permanência, Saída e Afastamento de Estrangeiros do Território Nacional (Decreto-Lei n. ${ }^{\circ} 244 / 98$, de 8 de Agosto), ao alargar o âmbito dos mecanismos de regularização de imigrantes ilegais, tornou Portugal um país mais atractivo para as redes de tráfico de mão-de-obra. Refiro-me muito especialmente ao artigo 88. ${ }^{\circ}$, que estabelece: "Em casos excepcionais de reconhecido interesse nacional ou por razões humanitárias, o Ministro da Administração Interna pode conceder a autorização de residência a cidadãos estrangeiros que não preencham os requisitos exigidos no presente diploma".

O que é interessante notar é que, sob o impacto conjugado da adesão de Portugal à Convenção de Schengen e da entrada em vigor do Decreto-Lei n. ${ }^{\circ} 244 / 98$, a imigração ilegal em Portugal começa a sofrer algumas mudan-

\footnotetext{
3 Intervenção do ministro da Administração Interna, Alberto Costa, in Diário da Assembeia da República, 29 de Março, 1996: 1685-1687.
} 
ças estruturais particularmente relevantes. Estas mudanças estão associadas à deslocação das principais zonas emissoras ou distribuidoras dos países de língua oficial portuguesa para os países do Leste europeu, região a partir da qual, desde os inícios dos anos noventa, se estruturam as principais redes de tráfico de mão-de-obra activas na União Europeia (EU).

Em suma, a regulação dos fluxos nesta segunda fase tinha como objectivo não obstacularizar os interesses geoestratégicos de Portugal, o mesmo é dizer manter a liberalidade de concessão de vistos de curta duração a migrantes originários dos PALOP e do Brasil. Tinha ainda como objectivo incluir no enquadramento legal um mecanismo de regularização excepcional de imigrantes ilegais, com base em intuitos humanitários, que permitiria esvaziar eventuais bolsas de imigrantes ilegais provenientes de países lusófonos que, entretanto, se viessem a formar.

Novamente o quadro regulador estava em dissonância com a realidade. Legislava-se para o tipo de fluxos que tinham entrado no país até meados dos anos 90, quando de facto Portugal, com a sua adesão ao Espaço Schengen, se tornara particularmente atractivo para fluxos de novas origens.

O legislador parece não se ter apercebido de que a entrada de Portugal no Espaço Schengen abria as portas do país aos titulares de vistos de curta duração emitidos por um qualquer país do Espaço Schengen. Esta perda de controlo de um dos mais importantes mecanismos de regulação dos fluxos teve como consequência a formação de uma nova bolsa de ilegais, desta vez provenientes de países com os quais Portugal não tinha quaisquer vínculos históricos ou ligações económicas, os países do Leste Europeu.

\section{A fase da supremacia do mercado}

Nas vésperas da promulgação do Decreto Lei n. ${ }^{\circ}$ 4/2001, de 10 de Janeiro, estavam pendentes no Serviço de Estrangeiros e Fronteiras (SEF) 41.401 pedidos de autorização de residência ao abrigo do referido artigo $88 .^{\circ}$ do Decreto-Lei n. ${ }^{\circ} 244 / 98$, ou seja, sabia-se estarem a residir ilegalmente no país pelo menos 41401 pessoas, das quais uma parte significativa era oriunda do Leste Europeu.

Foi para promover a legalização destes imigrantes e para responder às fortes pressões dos lobies da construção civil e obras públicas e da indústria do turismo que se promulgou o Decreto-Lei n. ${ }^{\circ} 4 / 2001$ ao abrigo do qual se regularizou a permanência em território nacional de 184000 imigrantes entre 2001 e 2003.

Com a entrada em vigor do Decreto-Lei n. ${ }^{\circ} 4 / 2001$, o quadro migratório em Portugal vai ser substancialmente alterado, particularmente no que concerne a regulação dos fluxos e a integração dos imigrantes. Antes de mais, 
porque, ao contrário das anteriores regularizações extraordinárias de 1992/93 e 1996, que foram amnistias gerais, isto é, destinaram-se a legalizar todos os imigrantes entrados no país até determinada data, o Decreto-Lei n. ${ }^{\circ}$ 4/2001 só permitiu a legalização de trabalhadores imigrantes detentores de um contrato de trabalho previamente registado no Ministério do Trabalho.

Verifica-se assim uma drástica mudança na política migratória nacional, uma vez que enquanto nos anos 90 se reconhecia que a ineficácia dos mecanismos de regulação dos fluxos migratórios levava à criação de bolsas de ilegais constituídas essencialmente por imigrantes provenientes dos PALOP, cujo projecto migratório era de longo prazo e a quem portanto se tornava necessário permitir a inclusão no tecido social português para evitar maiores fracturas sociais num futuro próximo, em 2001 o que se fez foi validar a posteriori o funcionamento do mercado, reconhecendo tacitamente a total inoperância dos mecanismos de regulação existentes.

Mais, valida-se a posteriori o funcionamento do mercado, parecendo o legislador tomar como garantido que as necessidades de mão-de-obra desse mesmo mercado eram conjunturais e não estruturais e que portanto a legalização não necessitava de ser vista como um primeiro passo num processo de integração, mas apenas como um recurso temporário à falta de mão-de-obra existente. Assim, concedem-se apenas autorizações de permanência válidas por um ano, renováveis até um máximo de cinco anos.

Ao entrar no espaço Schengen, Portugal tinha deixado de ser atractivo essencialmente para as suas ex-colónias e tinha passado a integrar o sistema migratório europeu, em que uma das principais pressões migratórias vem do Leste Europeu. A esta nova situação, o poder político respondia com amnistias parciais, apenas destinadas a trabalhadores que pudessem provar a existência de vínculos laborais, e com a concessão de autorizações de permanência temporárias.

Pareciam justas as críticas do executivo PSD/CDS ao anterior governo, quando afirmava no preâmbulo do Decreto-Lei n. ${ }^{\circ} 34 / 2003$, de 25 de Fevereiro: "o fluxo de imigração ilegal não só não diminuiu como, por força desta legislação flexível, aumentou de forma acentuada, tornando-se cada vez mais visível a precariedade do acolhimento e integração destes imigrantes". Parecia também um objectivo politicamente correcto justapor à primazia do mercado na política migratória "políticas de carácter humanista ao nível de acolhimento e de integração dos imigrantes que residem no nosso país". ${ }^{4}$

${ }^{4}$ Preâmbulo do Decreto-Lei n. ${ }^{\circ}$ 34/2003. 
Mudou-se de governo, mudou-se aparentemente de política. Desta feita, à anterior primazia do mercado, do Decreto-Lei n. ${ }^{\circ}$ 4/2001 do governo PS, corresponderia agora uma orientação integracionista dos imigrantes a residir no país e de "combate firme à imigração ilegal", do governo de coligação PSD/CDS.

E, em nome da "integração efectiva dos imigrantes", o novo quadro legal revoga o regime das autorizações de permanência, estabelece um limite máximo de entradas de imigrantes económicos e exige para a concessão do reagrupamento familiar "uma real ligação do requerente ao País".

Pela primeira vez definia-se qual era o volume máximo de entradas que o país pretendia receber ${ }^{6}$ e flexibilizavam-se os mecanismos de concessão de vistos de trabalho, para melhor atingir esse objectivo. Estas medidas de regulação dos fluxos saldaram-se por um enorme fracasso, como recentemente reconheceu o Director do SEF, Manuel Jarmela Palos, ao afirmar: "A quota era de 8500 pessoas e até agora só cento e pouco beneficiaram dela. Neste aspecto é um falhanço rotundo das políticas." De facto, é um falhanço, porque os imigrantes continuaram a entrar preferencialmente com vistos de curta duração e a fixar-se ilegalmente no país.

Quando este quadro legislativo entrou em vigor era possível argumentar que a nova linha orientadora, reiterada no discurso político de primazia à integração dos imigrantes e de combate à imigração ilegal, justificava o pendor mais restricionista da nova legislação no tocante à regulação das entradas. Mas, pouco mais de um ano passado sobre a promulgação do

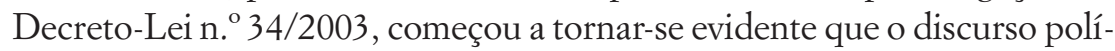
tico e a prática política estavam mais uma vez em dissonância. De facto, com a publicação do Decreto Regulamentar n. ${ }^{\circ}$ 6/2004 de 26 de Abril, o que se fez foi novamente introduzir mecanismos de regularização extraordinários. Desta feita, e ao abrigo do Artigo $71^{\circ}$ do referido decreto, foi aberto um período de registo, para posterior regularização, de 45 dias, para os trabalhadores imigrantes entrados até 12 de Março de 2003 que tivessem sido contribuintes, pelo menos 90 dias, para a Segurança Social e para a Administração Fiscal. Ou seja, longe de estancar a imigração ilegal e o comércio ilícito dos contratos de trabalho, o que o Decreto Regulamentar n. ${ }^{\circ}$ 6/2004 veio fazer foi mais uma vez reconhecer a inoperância dos mecanismos de regulação dos fluxos e a primazia do mercado.

\footnotetext{
5 Intervenção do ministro da Administração Interna, Figueiredo Lopes, in Diário da Assembleia da República, 29 de Junho de 2002: 1007-1009.

${ }^{6}$ Inicialmente, definiu-se um tecto máximo de 6500 entradas, subsequentemente alargado para 8500.

${ }^{7}$ Entrevista do director do SEF ao Público de 29 de Agosto de 2005.
} 
Assim, ao abrigo do Acordo Luso-Brasileiro de 2003 e do artigo $71 .^{\circ}$ do Decreto Regulamentar n. ${ }^{\circ}$ 6/2004, inscreveram-se para regularizar a sua permanência no país mais de 80000 imigrantes em situação ilegal. Mais concretamente, a situação era a seguinte em Outubro de 2004.

\section{Inscrições para regularizar a permanência (Outubro de 2004)}

\begin{tabular}{ll}
\hline Acordo Luso-Brasileiro & 29.522 imigrantes \\
Artigo $71 .{ }^{\circ}$ do D.R. n. ${ }^{\circ}$ 6/2004 & 53.196 imigrantes \\
\cline { 2 - 2 } Total & 82.718 imigrantes \\
\hline
\end{tabular}

Fonte: Documentos não publicados do SEF

Destes 53196 registos, apenas 19676 são de imigrantes provenientes de países lusófonos, ou seja, $37 \%$, o que significa que Portugal está cada vez mais inserido no sistema migratório europeu. A lista das principais nacionalidades dos imigrantes que se registaram ao abrigo do Art. $71^{\circ}$ do Decreto Regulamentar n. ${ }^{\circ}$ 6/2004 demonstra isso mesmo.

Registos para Regularização de Permanência - Principais Nacionalidades

\begin{tabular}{l|c}
\hline \multicolumn{1}{c|}{ Nacionalidades } & Registos \\
\hline Angola & 5.672 \\
Brasil & 6.727 \\
Cabo Verde & 3.570 \\
Bulgária & 1.120 \\
China & 1.834 \\
Guiné & 1.153 \\
Guiné-Bissau & 2.585 \\
Índia & 1.589 \\
Marrocos & 2.585 \\
Moldávia & 2.380 \\
Paquistão & 1.426 \\
Roménia & 5.106 \\
Rússia & 890 \\
S. Tomé e Príncipe & 1.122 \\
Senegal & 2.756 \\
Ucrânia & 8.328 \\
\hline
\end{tabular}

Fonte: Documentos não publicados do SEF

O facto de a maioria dos imigrantes ilegais vir de países cada vez mais longínquos e sem qualquer vínculo a Portugal parece ainda não ter sido reconhecido pelas elites políticas portuguesas, que continuam a subscrever políticas de regulação dos fluxos como se a imigração fosse, como nos anos oitenta e noventa, essencialmente proveniente de países lusófonos. 
Em suma, esta última fase da política de regulação dos fluxos salda-se, mais uma vez, por um rotundo fracasso e pela constituição de uma nova bolsa de ilegais.

\section{A falência dos mecanismos de regulação dos fluxos}

Como acabámos de ver, a política de regulação dos fluxos nunca atingiu os objectivos que se propôs. Sem dúvida que a melhor prova disto é o facto de pelo menos $59 \%$ da população estrangeira com um título válido de residência, até 31 de Dezembro de 2003, ter obtido o referido título através de uma das regularizações extraordinárias. ${ }^{8}$

Ou seja, a política de regulação dos fluxos foi, independentemente do discurso político, desde o seu início até hoje, uma política reactiva, que reconheceu sucessivamente a falência dos mecanismos de regulação que implementou e se vê, por isso mesmo, na contingência de lançar amnistias gerais ou parciais para esvaziar as bolsas de imigrantes ilegais que se vão sucessivamente formando.

A pergunta que naturalmente se põe é se poderia ter sido de outro modo. Para alguns autores não podia. Há uma linha de pensamento, que se tornou dominante nos anos noventa, que defende a existência de uma crise política no controlo dos fluxos. Para estes autores, essa crise evidencia-se pela enorme discrepância entre os objectivos das políticas de regulação dos fluxos e os seus resultados. A discrepância entre objectivos e resultados é atribuída pelos proponentes desta corrente à confluência das forças de mercado com as forças dos direitos consignados no quadro jurídico das democracias liberais (Cornelius et al., 1994: 10).

Esta posição foi subscrita para o caso português por João Peixoto, ao afirmar que "a intervenção do Estado sofre constrangimentos crescentes, em larga medida devido às dinâmicas do mercado" (Peixoto, 2002: 483). O resultado desses constrangimentos crescentes é um Estado relativamente fraco na regulação dos fluxos e um mercado relativamente forte na determinação desses mesmos fluxos (ibid.: 495).

Esta linha de pensamento tem vários problemas. O mais relevante para a presente discussão é de natureza conceptual, uma vez que não distingue, na análise da acção estatal, a dimensão do acesso ao território da dimensão

\footnotetext{
${ }^{8}$ A estimativa de 59\% advém dos seguintes dados: nas regularizações de 1992/3 a 2001/2003 registaram-se 257.903 imigrantes, o número de residentes legais em 2003 era de 433.886 pessoas. Sabemos ter havido alguma duplicação de registos entre as regularizações de 1992/3 e 1996, mas esse efeito é parcial ou mais provavelmente totalmente eliminado pelo facto de não termos tido em conta na nossa estimativa as concessões de autorização de residência ao abrigo do artigo $88 .^{\circ}$ do Decreto-Lei n. ${ }^{\circ} 244 / 98$.
} 
da fixação no território. Ora, as burocracias, os mecanismos e as técnicas de controlo destas duas dimensões são totalmente diferentes.

$\mathrm{Na}$ dimensão fixação no território tendo a concordar com João Peixoto em que a acção estatal se encontra coarctada pelas dinâmicas do mercado, muito particularmente pelas dinâmicas do mercado informal e pela falta de mecanismos de controlo. No que respeita à dimensão acesso ao território entendo, na linha de John Torpey (2000), que até 1995 Portugal tinha as burocracias, os mecanismos de controlo, bem como o monopólio das técnicas de remoto controlo para uma efectiva regulação dos fluxos.

De facto, até à entrada em vigor da Convenção de Aplicação de Schengen, em Março de 1995, Portugal ainda não se encontrava inserido no sistema migratório europeu e era essencialmente atractivo para os imigrantes provenientes dos PALOP, pelo que nessa altura a regulação dos fluxos e o combate à imigração ilegal podiam ter sido essencialmente feitos pela política de concessão de vistos de curta duração. Lembremos que Portugal tinha até então o monopólio da sua concessão e se não foi criterioso e parcimonioso no seu uso foi porque não o quis ser. A meu ver não o quis ser, porque o discurso político dominante não era de facto o da "imigração zero" do Ministro da Administração Interna, Dias Loureiro; o discurso dominante e transversal às várias forças políticas era, como salientou recentemente Fernando Luís Machado, o "de um Portugal humanista e universalista" que toma uma tonalidade lusotropicalista e a que se junta o discurso do "Portugal país de emigração que pode e deve reagir melhor do que os outros à imigração" (Machado, 2005: 112). Com este entendimento, não admira que a entrada de alguns milhares de imigrantes provenientes dos PALOP com vistos de curta duração não fosse vista como um problema político ou social que necessitasse de mecanismos de regulação especiais. Promulgava-se legislação para regular os fluxos para a harmonizar com a Europa, não para mudar o status quo.

Desde 1995, Portugal perdeu o monopólio da concessão de vistos de curta duração. Insensível a este facto e às suas implicações, o legislador legislou em 1996 e novamente em 1998, sob pressão das Associações de Imigrantes, da Igreja Católica e do Partido Socialista, para facilitar e promover a integração dos imigrantes residentes no país independentemente do seu estatuto legal, esquecendo-se aparentemente de legislar para regular os fluxos e para combater a imigração ilegal.

\footnotetext{
9 Ver discurso do ministro da Administração Interna, Dias Loureiro, à Assembleia da República, sobre política de imigração, em que toda a tónica do discurso é posta nos desequilíbrios demográficos mundiais e na harmonização com a Europa e não na realidade migratória nacional (in Diário da Assembleia da República de 27 de Março de 1992: 1364-1367).
} 
Esqueceu-se de regular os fluxos e de combater a imigração ilegal, a meu ver, porque o boom da construção civil e obras públicas que o país viveu de 1996 a 2003 e as necessidades de mão-de-obra da industria do turismo assim o exigiam. E, de facto, o mercado de trabalho absorvia, ainda que na economia informal e de forma precária, a esmagadora maioria dos que entravam com vistos de curta duração e posteriormente se fixavam.

Em 2003, com o país em recessão económica, estabelece-se, pela primeira vez, uma quota máxima de entradas e afirma-se uma profunda determinação de combate à imigração ilegal. Parecia o início de uma política de regulação dos fluxos, mas não o foi porque os mecanismos de preenchimento da quota se mostraram totalmente inoperacionais e porque, em vez de se combater a imigração ilegal, se deu mais uma vez primazia às necessidades do mercado e desta vez também às necessidades dos cofres do Estado.

\section{Para uma política de regulação dos fluxos}

Qualquer política de regulação dos fluxos tem que ter em conta os condicionalismos que o nosso passado histórico, os nossos interesses geoestratégicos e a nossa posição no sistema mundo nos impõem. Sem ter em conta estes condicionalismos é impossível delinear uma política coerente e eficaz. No momento presente, os principais condicionalismos a ter em conta são:

1. A perda de monopólio da concessão de vistos de curta duração, a que já me referi. Esta perda tem como principal consequência que a regulação dos fluxos não possa ser pensada essencialmente a priori, isto é, por mecanismos de triagem e de controlo na origem; tem que ser pensada e executada em conjugação com mecanismos a posteriori, isto é, por mecanismos de regulação em Portugal.

2. Não sendo politicamente aceitável evitá-la, nem tão pouco possível, dadas as garantias legais que o direito à reunificação familiar tem vindo progressivamente a ganhar, quer no enquadramento jurídico da UE, quer no enquadramento jurídico nacional, a política migratória deverá assumir que a corrente migratória dos PALOP para Portugal se manterá pelo menos nos níveis verificados na última década. Este condicionalismo implica que, ab initio, sejam pensados mecanismos promotores de integração e de futura pertença à sociedade portuguesa por parte desta população, cuja fixação vem auto-sustentar a população de ancestralidade africana a residir em território nacional. Esta corrente migratória, devido à sua especificidade (migração pós-colonial; em cadeia; baseada em redes migratórias informais; de fraquíssimas qualificações profissionais e integrada em grupos/comunidades em que uma percentagem significativa é de nacionalidade portuguesa), aumenta substancialmente os riscos de criação e desenvolvimento de uma 
etno-classe situada na base da estrutura social portuguesa, que evidencia sintomas de vir a desenvolver nas segundas e terceiras gerações culturas adversariais.

3. Continua a ser politicamente incentivada a emigração de brasileiros para Portugal. A assinatura do Acordo de Cooperação Portugal/Brasil de 2001 e o Acordo Luso-Brasileiro de 2003, apenas vêm confirmar a discriminação positiva de que este fluxo tem sido e continua a ser alvo. O enquadramento jurídico desta corrente migratória é, não apenas específico, mas, como afirmei, altamente privilegiado, o que por si mesmo é um condicionalismo inultrapassável na elaboração de uma política migratória.

4. Decorre dos instrumentos internacionais sobre refugiados e populações com necessidades de protecção temporárias, de que Portugal é subscritor, e que na sua essência já se encontram vertidos no ordenamento jurídico nacional, um quarto condicionalismo. A protecção por razões humanitárias que Portugal tem concedido é numericamente pouco significativa e dada a nossa posição geográfica e o nível de bem-estar nacional comparado com os dos nossos parceiros da UE não são de prever grandes alterações no volume deste tipo de fluxo. Acresce, contudo, que outros factores devem aqui ser tidos em consideração, como, por exemplo, o facto de a Espanha estar a ser procurada por imigrantes marroquinos, magrebinos e de outras procedências em África. O facto de a costa sul de Portugal ser muito mais inacessível que a costa espanhola, tanto em termos de distância como em termos das características de navegação, tem provavelmente evitado que esses imigrantes tentem a entrada no nosso país. Contudo, a crescente dificuldade de entrar e permanecer ilegalmente em Espanha criará, com certeza, incentivos quer ao aparecimento de tentativas isoladas de travessia quer ao desenvolvimento de um mercado de tráfico de migrantes, mercado esse que já existe em Marrocos. Embora se possa argumentar que o nosso país serviria apenas de ponto de passagem para a Espanha e, portanto, que estes contingentes não tentariam a sua fixação em território nacional, convém considerar a hipótese de, ao abrigo das cláusulas existentes no ordenamento jurídico português de protecção humanitária, uma parte deste fluxo vir a permanecer em Portugal. De facto, a sua não consideração pode criar o risco de aparecimento de mais um factor de fricção nas relações triangulares: Portugal, Espanha e Marrocos.

5. O quinto e último condicionalismo decorre do actual contexto migratório. É imperativo para um Estado democrático garantir de direito e de facto os direitos económicos e sociais dos estrangeiros que residem e trabalham no país, o mesmo é dizer ser capaz de desmantelar as redes de tráfico e de extorsão que se encontram a operar no território nacional, bem 
como regular o mercado de trabalho, particularmente no que concerne à formalidade das relações laborais. Ou seja, é necessário devolver ao imigrante os direitos económicos e sociais de cidadania que a Constituição portuguesa the confere para que possa livremente vender a sua força de trabalho no mercado formal que melhor a remunera, permitindo-lhe ser o principal actor e decisor do seu próprio projecto migratório.

Conhecemos razoavelmente os condicionalismos que terão de ser tidos em conta na elaboração de uma política migratória de regulação dos fluxos, contudo o mesmo não se verifica com os objectivos a que essa política deverá obedecer. E isto porque quer a definição dos objectivos a atingir, quer a sua hierarquização, são sobretudo função da percepção e vontade dos decisores políticos.

Sobre este tema, e no actual contexto, existem duas perguntas extremas que só são passíveis de resposta política e que podem ser formuladas da seguinte forma:

- pretende o governo adoptar uma política migratória pró-activa, que tenha como objectivo aumentar significativamente o capital humano existente, alterando com a sua intervenção a fraquíssima estrutura de recursos humanos que tipifica a sociedade portuguesa?

- ou pretende o governo adoptar uma política migratória que tenha como primordial objectivo diminuir significativamente os custos laborais e satisfazer a pressão de sectores económicos pouco competitivos, maximizando os lucros económicos de curto prazo e diferindo os custos sociais de médio e longo prazo deste tipo de política?

Como os objectivos que subjazem à formulação das perguntas que acabo de enunciar não são mutuamente exclusivos, é de esperar que a definição política de objectivos que venha a ser adoptada tente simultaneamente promover o capital humano existente e satisfazer as necessidades conjunturais do mercado de trabalho.

É efectivamente a prossecução simultânea destes dois objectivos que, no presente momento, deveria nortear a definição da política migratória de regulação dos fluxos. Primeiro porque, a médio prazo, será esta política que maximizará os benefícios económicos dos vários actores e agentes directa e indirectamente envolvidos; segundo porque a prossecução, em simultâneo, destes objectivos permitirá gerar excedentes significativos para os cofres do Estado, parte dos quais poderão e deverão ser usados para minimizar os custos sociais de médio e longo prazo. É no entanto neces- 
sário enfatizar que os benefícios decorrentes da adopção dos objectivos enunciados são proporcionais ao grau de formalidade que o governo for capaz de impor às relações laborais dos imigrantes no mercado de trabalho nacional. Ou seja, quanto maior for a incorporação dos imigrantes na economia formal, tanto maiores serão os benefícios decorrentes da sua presença em território nacional e tanto menores serão as probabilidades de eles serem explorados.

A definição de uma política migratória que privilegie uma componente pró-activa significativa tem, contudo, que basear-se necessariamente em informação pertinente e rigorosa, que fundamente a decisão política e minimize a respectiva margem de erro, nomeadamente na definição do perfil do/da imigrante cuja vinda se quer promover e do volume do fluxo migratório que se permitirá entrar. Ou seja, requer liderança política, quer para garantir a coordenação e articulação eficaz entre os vários agentes institucionais que necessariamente terão de estar envolvidos na sua implementação, quer para combater o mercado de trabalho informal e o funcionamento das redes de tráfico e de colocação de mão-de-obra.

\section{Referências Bibliográficas}

Borjas, George (1996), "The New Economics of Immigration", The Atlantic Monthly, Novembro, 72-80.

Cornelius, Wayne; Martin, Philip; Hollifield, James (orgs.) (1994), Controlling Immigration. A Global Perspective. Stanford: Stanford University Press.

Director do SEF (2005), Entrevista do Director do SEF, Manuel Jarmela Palos, ao Público de 29 de Agosto.

Hammar, Thomas (1992), "Laws and Policies Regulating Population Movements: A European Perspective”, in Mary Kritz; Lin Lim; Hanic Zlotnik (orgs.), International Migration Systems. A Global Approach. Oxford: Clarendon Press, 245-262

Ministro da Administração Interna (1992), Intervenção do Ministro da Administração Interna, Dias Loureiro, na Assembleia da República, in Diário da Assembleia da República de 27 de Março, 1364-1367

Ministro da Administração Interna (1996), Intervenção do Ministro da Administração Interna, Alberto Costa, na Assembleia da República, in Diário da Assembleia da República de 29 de Março, 1685-1687.

Ministro da Administração Interna (2002), Intervenção do Ministro da Administração Interna, Figueiredo Lopes, na Assembleia da República, in Diário da Assembleia da República de 29 de Junho, 1007-1009.

Machado, Fernando Luís (2005), "Des étrangers moins étrangers que d'autres? La régulation politico-institutionnelle de l'immigration au Portugal", in Évelyne Ritaine 
(org.), L'Europe du Sud face à l'immigration. Politique de l'Étranger. Paris: Presses Universitaires de France, 109-146.

Nunes, Luis Pedro (1990), "Radiografia do estrangeiro fixado em Portugal”, Público, 17 de Julho.

Peixoto, João (2002), “Strong Market, Weak State: The Case of Recent Foreign Immigration in Portugal", Journal of Ethnic and Migration Studies, 28(3), 483-497.

Pires, Rui Pena et al. (1984), Os retornados. Um estudo sociográfico. Lisboa: IED.

S/A (1991), "CGTP lança alerta sobre situação de trabalhadores clandestinos", Diário de Notícias, 15 de Outubro.

Torpey, John (2000), "States and the Regulation of Migration in the Twentieth-Century North Atlantic World”, in Peter Andreas; Timothy Snyder (orgs.), The Wall around the West. State Borders and Immigration Controls in North America and Europe. New York: Rowman \& Littlefield Publs., Inc., 31-54.

Zolberg, Aristide (1989), "The New Waves: Migration Theory for a Changing World”, International Migration Review, XXIII(3), 403-429.

\section{Legislação citada}

\begin{tabular}{|c|c|c|}
\hline Ano & Diploma & Tema \\
\hline 1975 & Dec.-Lei n. ${ }^{\circ} 308-A / 75$, de 24 de Julho & Nacionalidade \\
\hline 1992 & Dec.-Lei n. ${ }^{\circ} 212 / 92$, de 12 de Outubro & Regularização Extraordinária de Estrangeiros \\
\hline 1993 & Dec.-Lei n. ${ }^{\circ} 59 / 93$, de 3 de Março & Entrada, Permanência e Expulsão \\
\hline 1996 & Lei $.^{\circ} 17 / 96$, de 24 de Maio & Regularização Extraordinária de Estrangeiros \\
\hline 1998 & Dec.-Lei n. $244 / 98$, de 8 de Agosto & Entrada, Permanência e Expulsão \\
\hline 2001 & Dec.-Lei $\mathrm{n}^{\circ} 4 / 2001$, de 10 de Janeiro & Entrada, Permanência e Expulsão \\
\hline 2003 & Dec.-Lei ${ }^{\circ}{ }^{\circ} 34 / 2003$, de 25 de Fevereiro & Entrada, Permanência e Expulsão \\
\hline 2004 & $\begin{array}{l}\text { Decreto Regulamentar n. } .^{\circ} \text { 6/2004, } \\
\text { de } 26 \text { de Abril }\end{array}$ & Regulamenta o Dec.-Lei n. ${ }^{\circ} 34 / 2003$ \\
\hline
\end{tabular}

